\title{
COMMENTARY
}

\section{Hypothermia in trauma patients: predicting the big chill}

\author{
Brett $\mathrm{H}$ Waibel* \\ See related research by Lapostolle et al., http://ccforum.com/content/16/4/R142
}

\begin{abstract}
Physicians commonly ignore hypothermia, an oftenunderappreciated event associated with mortality in trauma patients, in general due to its prevalence and belief that it is secondary to the injury itself (secondary hypothermia). Over the past several decades, hypothermia in trauma has been studied concerning its effects on mortality; however, very little has been done to identify the major risk factors associated with it. The study by Lapostolle and colleagues has attempted to incorporate environmental risk factors and prehospital care along with more traditional variables for the prediction of hypothermia at admission.
\end{abstract}

I was recently asked to provide an evaluation of the study by Lapostelle and colleagues concerning the evaluation of risk factors associated with hypothermia at arrival to definitive care [1]. In addition to collecting common variables, such as patient physiology and wounding characteristics, they have collected a host of prehospital variables, including environmental conditions, physical presentation of the patient at the scene, and emergency medical services prehospital care. This information was combined in a multivariate logistic regression model in an attempt to identify those characteristics that correlate best with admission hypothermia. In this manner, they attempt to help identify some of those unthought-of variables not really discussed in previous literature.

Hypothermia is felt to be primarily a secondary event, that is, due to the injury itself. Animal models have shown a decrease in core body temperature correlating with blood pressure and not the level of resuscitation [2]. Human studies, while observational in nature, give a

*Correspondence: Brett.Waibel@vidanthealth.com

Department of Surgery, Division of Trauma and Surgical Critical Care, Brody School of Medicine, East Carolina University, Greenville, NC 27858, USA more mixed picture [3-6]. Physiology and injury severity seem to be the primary predictors of hypothermia, and these findings often correlate with the volume of resuscitation. In the studies to date, the majority of risk factors discussed appear to be secondary to the injury itself and the underlying changes to physiology. Factors commonly cited for hypothermia in trauma patients include extremes of age, environmental stresses, impaired neurological state or mobility, and subsequent care by health services [7]. Head injury and alcohol/drug abuse are often cited as risk factors. But rarely are these factors actually measured or incorporated into models. Little effort has been placed in the prehospital environmental conditions and care that might cause a primary hypothermia (heat loss exceeds heat generation despite normal thermogenesis).

In their study, they identified worsening physiology (Revised Trauma Score) to correlate with hypothermia. Additionally, intubated patients were at a higher risk of hypothermia. These two findings have been identified in prior studies. What is unique to this study is finding an inverse correlation of ambulance and infused fluid temperatures with admission hypothermia. While more rigorously examined in this study, control of environmental and infusion temperatures to prevent admission hypothermia has been inferred in other studies. Husum and colleagues [8] used warmed IV fluids along with other simple maneuvers to reduce conduction and radiation heat loss (removal of wet clothing, the use of dry blankets, windshields), as part of their resuscitation of landmine victims in the prehospital setting [8]. They showed a reduction of hypothermia on arrival to the relief hospital from $18.6 \%$ down to $3.3 \%$. In a similar fashion, the United States military has shown a reduction in hypothermia in their wounded patients using an aggressive rewarming protocol, which includes the use of warmed IV fluids, from $7 \%$ to less than $1 \%[9,10]$. Recently, we presented an abstract at the Society of Critical Care Medicine's annual meeting looking at fluid warmers in the prehospital setting to prevent hypothermia. The addition of fluid warmers to the ambulances was associated with a $22 \%$ relative risk reduction in 
admission hypothermia over historical controls (20.0\% versus $15.6 \%$ ) [11].

The paper also suggests that those patients with a head injury or who are unclothed have a reduced incidence of hypothermia. A protective effect of head injury and exposure seem contradictory to common sense. There has often been a worry of head injury causing dysregulation of thermoregulatory control; and exposure of the patient to the environment (unless with wet clothing) should hasten, not protect, the patient. To further the confusion, the authors actually take an opposing stance in their discussion, advocating that clothing should not be removed in the prehospital setting. I would be interested to hear more from the authors concerning their thoughts on these findings.

Their findings mirror other hypothermia studies in that the hypothermic cohort is significantly sicker with subsequent changes in physiology predominating as the primary reason for hypothermia. However, this study suggests that part of the hypothermia problem in trauma patients is a primary hypothermia, as increasing ambulance and infusion fluid temperature correlate with euthermia. When taken as a pure thermodynamic problem, the use of warmed IV fluids and ambulance should have minimal effect on the development of hypothermia. However, this paper, along with others, suggests minimizing conductive, convective, and radiation loss is more important than previously thought.

It is my personal belief that there is a mixture of these two events, a primary and secondary hypothermia, that develops in trauma patients. I believe the iatrogenic heat loss that occurs in the prehospital setting amplifies the effect of the secondary hypothermia created by the injury, which predominates in the most severe hypothermia cases. Care should be taken to avoid loss of heat via conductive, convective and radiation because of this effect. It is the attempts by this group to identify those environmental conditions, as well as emergency medical services care patterns, that affect the development of hypothermia in trauma patients that should be most congratulated.

\section{Competing interests}

The author declares that he has no competing interests.

Published: 21 September 2012

\section{References}

1. Lapostolle F, Sebbah JL, Couvreur J, Koch FX, Savary D, Tazarourte K, Egman G, Mzabi L, Galinski M, Adnet F: Risk factors for onset of hypothermia in trauma victims: The HypoTraum study. Crit Care 2012, 16:R142.

2. Bergstein JM, Slakey DP, Wallace JR, Gottlieb M: Traumatic hypothermia is related to hypotension, not resuscitation. Ann Emerg Med 1996, 27:39-42.

3. Gregory JS, Flancbaum L, Townsend MC, Cloutier CT, Jonasson O: Incidence and timing of hypothermia in trauma patients undergoing operations. J Trauma 1991, 31:795-8; discussion 798-800.

4. Bernabei AF, Levison MA, Bender JS: The effects of hypothermia and injury severity on blood loss during trauma laparotomy. J Trauma 1992, 33:835-839.

5. Ireland S, Endacott R, Cameron P, Fitzgerald M, Paul E: The incidence and significance of accidental hypothermia in major trauma--a prospective observational study. Resuscitation 2011, 82:300-306.

6. Waibel BH, Newell MA, Durham CA, Barrett MR, Schlitzkus LL, Rotondo MF: Predictors of hypothermia in trauma patients. Crit Care Med 2010, 38 (12 Suppl):Abstract 208.

7. Kirkpatrick AW, Chun R, Brown R, Simons RK: Hypothermia and the trauma patient. Can J Surg 1999, 42:333-343.

8. Husum H, Olsen T, Murad M, Heng YV, Wisborg T, Gilbert M: Preventing postinjury hypothermia during prolonged prehospital evacuation. Prehosp Disaster Med 2002, 17:23-26.

9. Nesbitt M, Allen P, Beekley A, Butler F, Eastridge B, Blackbourne L: Current practice of thermoregulation during the transport of combat wounded. J Trauma 2010, 69 Suppl 1:S162-167.

10. Eastridge BJ, Jenkins D, Flaherty S, Schiller H, Holcomb JB: Trauma system development in a theater of war: Experiences from Operation Iraqi Freedom and Operation Enduring Freedom. J Trauma 2006, 61:1366-1372, discussion 1372-1373.

11. Waibel B, Ferguson J, Newell M: Use of warmed intravenous fluids during transport to trauma patients to prevent admission hypothermia. Crit Care Med 2011, 39(12 Supplement):49.

doi:10.1186/cc11473

Cite this article as: Waibel $\mathrm{BH}$ : Hypothermia in trauma patients: predicting the big chill. Critical Care 2012, 16:155. 